\title{
Chapter 10 Operating experience feedback from French research reactors
}

Operating experience feedback is vital for maintaining and improving the safety of all nuclear facilities. In the case of research reactors, this operating experience feedback is based on:

- the lessons learned from events ${ }^{246}$ that have occurred at nuclear facilities internationally, whether research reactors, nuclear power reactors or other types of facility;

- the detailed analysis (up to identification of the root cause) of events that have occurred at French research reactors, with the definition and implementation of measures to prevent them occurring again;

- information shared between the operators of research reactors and, more broadly, with other stakeholders, including on an international scale (notably under the aegis of the IAEA).

Regarding the lessons learned from events that have occurred at nuclear facilities internationally, three elements may be highlighted:

246. The expression used now in France is "event", as the expression "incident" refers instead to the operating conditions of the second category of the deterministic safety analysis. An ASN guide published on October 21, 2005, draws a distinction between "interesting events" and "significant events". "Interesting events" (i.e. those affecting safety, radiological protection or the environment) are events whose "immediate importance does not justify an individual analysis but whose repetitive character may be indicative of a problem calling for a detailed analysis". 
- firstly, the need to take into account reactivity accidents - including the BORAXtype accident - in the design of French research reactors, given the past accidents of this type that have occurred internationally (see chapters 4 and 8 of this document);

- the investigations following the Chernobyl accident, which occurred in 1986, into the correct management of protection inhibitions and temporary connections ("shunts"). These investigations, prompted by IPSN, notably resulted in the removal of the possibility of disabling some safety actions and the introduction of measures to better protect access to mechanisms allowing the adjustment of research reactor safety thresholds;

- the investigations following the 2011 accident at the Fukushima Daiichi nuclear power plant, which led to the "stress tests" (ECS) covered in section 10.2.

In the case of events linked to anomalies or deviations detected during the operation of French research reactors, experience is shared among operators and their facility managers via ad hoc bodies, in addition to the event being identified, reported to ASN if it is categorized as significant ${ }^{247}$ and managed according to the standard INB process. For its part, IRSN performs, in addition to analyzing each event and the measures proposed by the operator concerned to prevent its recurrence, a "second-level" analysis, which is broader and covers the various types of INB (research reactors, power reactors and fuel cycle facilities).

Unlike in the case of power reactors, it is harder to immediately apply the lessons learned from an event affecting one research reactor to other research reactors, given their diversity in terms of design and technology. However, the analysis of certain events, concerning lifting equipment, measurement systems, I\&C racks, iodine filters or even organizational systems, for example, may provide useful lessons for several facilities. In this way, the discovery in 2012 of an incorrectly positioned air sampling tube $^{248}$ in the ORPHÉE reactor stack led ASN to alert all INB operators regarding the matter. Several other concerns common to research reactors are covered by specific basic safety rules (including purification equipment on ventilation systems and protective measures against fire risks - see section 6.2).

Operating experience feedback from research reactors can also be used to assess the changes in the dose received by workers at the facilities over several years and draw up, where necessary, actions to reduce the dose received by personnel, notably by applying radiological protection principles.

At this point, it should be recalled (see section 4.1 of this document) that, alongside the operators of French research reactors, IRSN, in its role as coordinator for France, sends the IAEA annual reports on notable events that have occurred in these reactors in cases where the lessons learned are worth sharing at an international level. These reports are added to the IRSRR system database, used by the IAEA, which contains all

247. The criteria for reporting significant events are specified in an ASN guide dated October 21, 2005.

248. Sampling for measuring tritium. 
the reports sent by the various countries. The IRSRR database is an information and knowledge resource available to operators ${ }^{249}$, who can take it into account, notably during facility safety reviews.

Lastly, it should also be recalled, as indicated in section 6.1, that operators inform the public of any significant events that occur at their facilities, providing the analysis that they have completed and the measures taken to avoid repeat events, in accordance with the provisions of the TSN Act.

\subsection{Trends, some notable events and their management}

\subsubsection{Trends}

At end of June 2018, the event database maintained by IRSN since June 1972 contained 1,515 events that had affected French research reactors, together with their classification on the INES scale. This corresponds to three events per reactor per year on average $^{250}$. The events are listed in the ASN's annual (public) reports.

Several major families of events and trends may be identified:

- events that are not specific to research reactors:

- the discovery of foreign bodies in fuel elements,

- the faulty operation of or damage to components (fuel elements, internal structures, reactor coolant systems, absorbers mechanisms, safety valves, diesel generators, lifting equipment, etc.), up to fuel melt (SILOE, 1967),

- leaks from pools or tanks (notably in the case of the SILOE reactor between 1965 and 1986), water infiltration into fissile material storage rooms,

- electrical insulation faults, loss of off-site electrical power,

- malfunctions in the ventilation systems and pressure loss in rooms, poor efficiency of iodine filters,

- incorrect safety threshold settings, non-compliance with operating rules or operating procedures (for example regarding the limits set to prevent criticality risks, access conditions for controlled areas or the frequency of in-service inspections);

249. In all cases, it is the national coordinators who are responsible for sending incident reports from the IRSRR, IRS, etc. databases to the operators in their country.

250. The average for pressurized water reactors in the nuclear power fleet, which are much more complex facilities than research reactors, is around 13 (significant) events per reactor per year (events affecting safety and radiological protection). It may be useful here to highlight that the number of events that occur at a nuclear facility does not, in itself, constitute an indicator of the level of safety of the facility. However, the in-depth analysis of each event is a vital learning resource. 
- events related to the specific design features of research reactors: objects falling into pools, heavy water system leaks, tritium releases (via the stacks or into the ground) from detritiation facilities, anomalies regarding natural convection valves, etc.;

- events linked to specific equipment, such as anomalies regarding the neutron channel thimbles (ORPHÉE, RHF) or cold sources (ORPHÉE, HFR). One example occurred at RHF, which experienced corrosion due to irradiation, detected from 1972, on the inside of the aluminum alloy thimbles (in AG3NET), more specifically on the "collimator plugs". These plugs seized due to corrosion caused by the formation of nitric acid, in turn resulting from radiolysis of the air ${ }^{251}$ subjected to neutron flux (which led to the air in the thimbles being replaced with helium, and, as the thimbles were gradually replaced, new Zircaloy thimbles being installed). Another example occurred in August 1988, when an error caused the rupture disks protecting RHF's vertical cold source against overpressure to crack and release, at the facility stack ( $45 \mathrm{~m}$ high), approximately $9 \mathrm{~m}^{3}$ of deuterium containing several tens of $\mathrm{TBq}$ of tritium;

- events linked to experimental devices and their use: the triggering of safety systems specific to these devices, chemical reactions with sodium or sodiumpotassium alloys, device explosions, etc.;

- operator exposure or the contamination of pools, buildings, rooms or people. Here it is relevant to mention the spillage of antimony 124 from a startup neutron source into the RHF pool in 1974. In the end, after numerous events ${ }^{252}$, this resulted in a combined release into the Isère River of $20 \mathrm{TBq}$ of this radioactive element (over 1974 and 1975);

- the discovery of undocumented radioactive sources or objects;

- outbreaks of fire, notably a fire in the electronics room of an experiment measurement facility (CABRI, 1979) and a deflagration in an electrical cabinet (RHF, 2000).

There have been several events linked to handling operations and lifting equipment:

- a traveling motor-reducer unit falling from a crane (OSIRIS, 1975),

- the rupture of a winch drive band (ULYSSE, 1975),

- a transportation container falling due to the overhead crane hook becoming detached from the block and tackle (ISIS, 1976),

- assembly (MASURCA, 1977) and rodlets (same reactor, 1989) falling,

- elements of an experimental loop falling into the pool (SILOE, 2004),

- the rupture of a hoist cable and a hook falling onto the "edge platform" (RHF, 2012),

- the rupture of a sling (RHF, 2013).

251. More specifically, radiolysis of traces of water in the air.

252. As reported in the press (for example Sciences \& Avenir $n^{\circ} 360$, February 1977). 
The risks associated with handling operations therefore require special attention ${ }^{253}$. An in-depth analysis should be performed on the various safety elements of these handling operations: the reliability of lifting equipment, handling sequences ${ }^{254}$, human and organizational factors, measures to limit the consequences of an item falling, etc.

In addition, between 1991 and 2007, the ventilation systems at the MASURCA facility malfunctioned repeatedly, with the loss of negative pressure in various rooms. This was due to fan failure or loss of electric power, which could be attributed to aged components. These elements were taken into account when these reactors were renovated.

Although the frequency of "human error" or "handling error" events tends to drop from the 2000s onward, cases of failure to comply with regulatory requirements or operating rules have emerged, associated with the gradual strengthening of safety documentation at research reactors (notably for their operation). The frequency of events concerning experiments and associated devices has fallen over the decades, indicating improved control.

It is interesting to note the appearance, from the 2000s, of events corresponding to the identification of gaps or imperfections in the safety demonstration (study anomalies, errors in the operational application of requirements, etc.), such as:

- "an error in the criticality safety evaluation, in the safety report, of a box containing surplus nuclear materials" (MASURCA, 2003);

- "the use of the equipment access hatch to the ring gallery in a way that is not covered by the safety documentation" (OSIRIS, 2005);

- "the incorrect formulation of the mass limit [in a] "hot laboratory" during the revision of the safety report in 2004" (MASURCA, 2012).

In the next section, some of the most notable safety events that have affected French research reactors are covered in more detail, together with the corrective measures taken as a consequence. A certain number of these events have been analyzed as part of safety reviews. These events, which generally occurred some years ago, have been selected for their educational interest, and more specifically due to the way in which they unfolded, the physical phenomena involved, the safety issues raised and the measures introduced as a response.

\subsubsection{Some notable events and their management}

\section{Recurring leaks in the SILOE reactor pool (1965-1986) $)^{255}$}

The design of the SILOE reactor pool was called into question by water leakage from this pool into the groundwater, which occurred between 1965 and 1972, then again in 1986.

253. This observation is also valid for nuclear power reactors.

254. The handling sequence refers to the sequence of movements in terms of horizontal and vertical movements, movement speed, the area or objects passed over, etc.

255. Le Matin and Le Monde newspapers, dated April 16, 1987, and October 23, 1987, respectively, reported on these events. 
The civil engineering structure of the SILOE reactor had two compartments:

- a compartment known as the "main pool", measuring $213 \mathrm{~m}^{3}$, which contained the reactor core - this was the pool that leaked;

- a compartment known as the "work pool", measuring $322 \mathrm{~m}^{3}$, arranged in a horseshoe layout around the main pool and generally used for storing and performing operations on experimental devices.

The first water leak from the main pool was detected in 1965 from the records of the makeup water added to compensate for the evaporation of water from the pool. The leak stopped in 1968 and reappeared in 1969. In 1970, a stream of bubbles was observed in the pool water, which made it possible to detect a crack between the ceramic tiles at the bottom of this pool (separated by araldite seals), near the foot of the "stool" supporting the reactor core. Leaktightness was restored by installing a stainless steel plate on the tiled floor, with a synthetic foam seal. However, the leak reappeared in 1971 due to the degradation of the seal caused by radiation. The leak was only sealed durably in 1972, with the installation of a flat, natural rubber seal held against the bottom of the pool with lead.

The total volume of contaminated water that entered the groundwater between 1965 and 1972 was estimated to be around 1,500 $\mathrm{m}^{3}$. The total activity released in this way, principally due to tritium, was estimated to be in the order of $2.7 .10^{11} \mathrm{~Bq}$. During work to replace the "stool ${ }^{256 "}$ of the reactor core grid in 1977, the pool was resealed by installing a layer of epoxy resin and glass wool fabric $4 \mathrm{~mm}$ thick on the tiled floor and up to a height of $75 \mathrm{~cm}$ on the vertical walls.

The ongoing leak in the pool notably led the nuclear safety department ${ }^{257}$ of the CEA to evaluate the potential radioactive releases into the groundwater in the hypothetical case of a BORAX-type accident, taking into account the contamination of the pool water (due to the accident) and the transfer of radionuclides through the groundwater to the Isère River (calculated to take 55 days). In this way, it was demonstrated that, even without purifying the contaminated water from the reactor pool, the added activity ${ }^{258}$ concentration in the Isère River would be low (in the order of $140 \mathrm{~Bq} / \mathrm{L}$ ). The study did, however, lead to the examination of measures to limit the consequences of such an accident with a leaky pool: purifying the pool water (starting the "hot layer" [see section 7.3.3] and "pool floor" systems would reduce the added activity concentration in the Isère River to $0.7 \mathrm{~Bq} / \mathrm{L}$ ), transferring the pool water to a tank at the SILOETTE facility, pumping water under the foundation raft, into pits, etc.

However, in November 1986, an increase of approximately $1 \mathrm{~m}^{3}$ in the makeup water added to the pool to compensate for evaporation was observed once again. After checking the leaktightness of various reactor systems, the reactor was shut down at the start of December 1986 for a detailed inspection of the main pool, suspected to be the source of the water leak. This inspection required the fuel elements to be unloaded,

256. This was replaced by a grid-stool-box assembly.

257. The forerunner of IPSN, which was created in 1976.

258. Due to all the fission products liberated by the core melt. 
the pool to be drained, the various reactor core structures to be dismantled and the tiling to be removed. The water was transferred from the pool to a tank designated for this purpose at a deliberately slow rate, in order to take advantage of the gradual drop in level to decontaminate the pool walls and thereby prevent the resuspension of radioactive particles in the air. Injecting inert gas ${ }^{259}$ under the foundation raft then made it possible to locate a hole approximately $5 \mathrm{~mm}$ in diameter in a corner at the bottom of the pool, as well as two small cracks. This event resulted in a release of approximately $30 \mathrm{~m}^{3}$ of water chiefly contaminated with tritium into the groundwater; the total activity was estimated at $2 \cdot 3 \cdot 10^{10} \mathrm{~Bq}$.

This event threatened the future of $\operatorname{SILOE}^{260}$, given the high cost of the work needed to return the reactor to good condition. However, the CEA decided to undertake this work so it could continue operating and performing experiments at this reactor, and scheduled the permanent shutdown of the MELUSINE reactor, which had been commissioned in 1958 and whose experiments could be transferred to the SILOE facility. The corresponding modifications, authorized by the SCSIN in summer 1987, were considerable. A stainless steel liner was installed in the main pool, welded to backing strips also made from stainless steel and fastened to the pool walls. A gap was left around the edge of the pool, equipped with a system to detect leaks and recover any leaks from the liner. Regarding the capacity of the pool to withstand a BORAX-type accident, while the leaktightness of the neutron channel penetrations seemed assured, the technical inspection highlighted the weakness of one of the pool walls. This led the operator to install a tank - known as a BORAX tank - able to deform and thereby absorb some of the energy that would be released in the event of such an accident ${ }^{261}$, in order to protect the liner and pool walls. With the same aim in mind, a stainless steel plate $20 \mathrm{~mm}$ thick, positioned on shock absorbers known as "resilient pads", was installed on the basemat, under the BORAX tank, in order to guarantee the mechanical resistance of the pool basemat to the pressure that would result from a BORAX-type accident. Liners were also installed in the decay tanks, with leak detection and water recovery systems. These various liners and tanks are shown in figure 10.1.

In addition, two more piezometers were installed in 1988 to improve groundwater monitoring.

Later on, the leaks in the SILOE reactor pool had consequences for the dismantling of this reactor, which are only mentioned briefly below.

The permanent shutdown and dismantling operations at the SILOE reactor were subject to a public inquiry and the associated operating license was awarded in January 2005. The final state, as envisaged by the CEA, was full cleanup of the walls of the reactor rooms. In this respect, the CEA set the following quantitative $\operatorname{targets}^{262}$ in 2008 :

259. The gas used was sulfur hexafluoride, SF6, which is non-toxic, non-flammable and practically insoluble in water, and has high chemical and thermal stability.

260. See footnote 245 .

261. The other part of this energy is dissipated by being expelled towards the top of the water.

262. In the information package related to the cleanup of structures (DIRAS), with a view to decommissioning. 


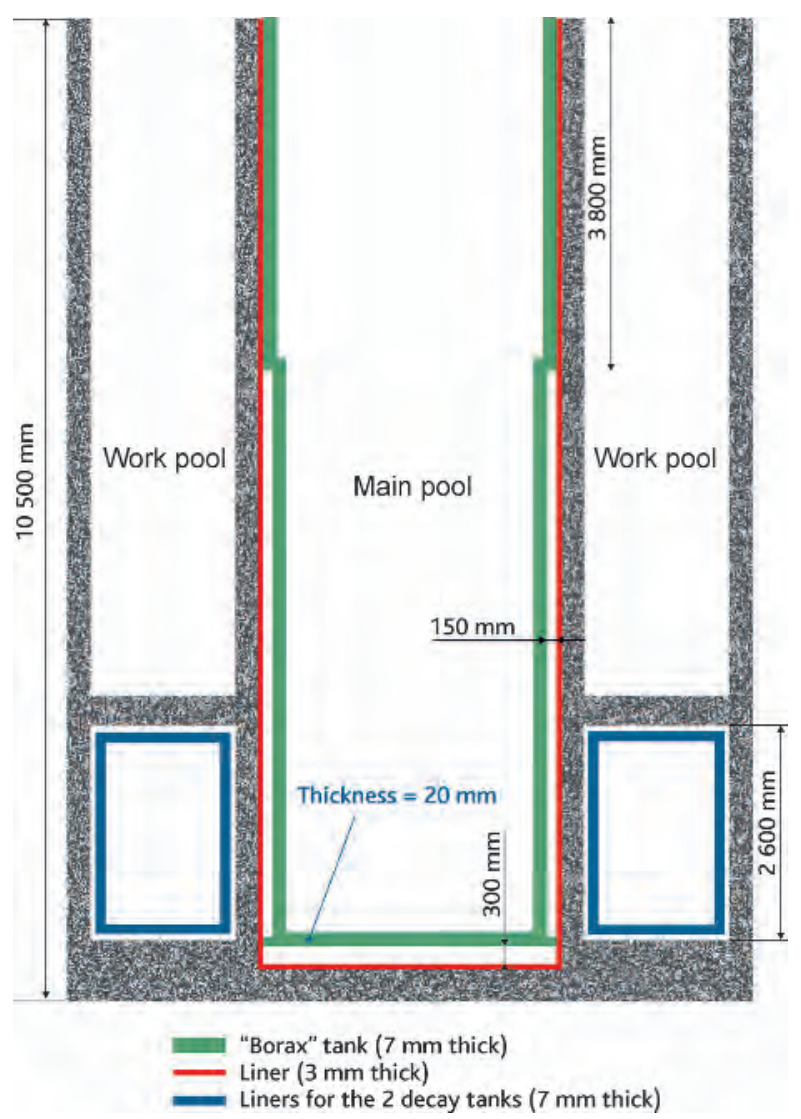

Figure 10.1. Pools and decay tanks at the SILOE reactor: tanks and liners installed in 1987-1988. (c) Georges Goué/IRSN.

- a theoretical "acceptable modeled value for residual activity" (VARMA), below which structures can be considered conventional, of $1 \mathrm{~Bq} / \mathrm{g}$ of concrete for $\beta \gamma$ emitters, excluding tritium, and of $100 \mathrm{~Bq} / \mathrm{g}$ for tritium;

- for $\beta \gamma$ emitters excluding tritium, a end of cleanup decision criterion, on the basis of the measurements performed for some radionuclides, of $0.4 \mathrm{~Bq} / \mathrm{g}$, lower than the previous value and incorporating an additional margin to take into account measurement uncertainties in particular.

At that point, the cleanup strategy for the reactor pool basemat and underlying ground had not been determined, as the pool needed to be removed before the level of contamination of these elements could be measured.

In 2010, the CEA suggested removing part of the foundation raft through its whole thickness, and across a surface area covering the whole of the main pool. In addition, given the uncertainties regarding the leak pathways through the thickness of the 
basemat, it suggested examining the vertical walls, stripped at the point where they met the thickness of the foundation raft, with a view to checking that there was no contamination at the various possible leak pathways in the concrete, along the length of the rebars and the prestressing cable ducts, and in the bitumen felt elements ensuring leaktightness.

In 2011, the CEA informed ASN of the presence of contamination in the thickness of the basemat around the prestressing cables and in part of the ground located under the basemat (locally, the specific activity reached $25 \mathrm{~Bq} / \mathrm{g}$ ). This meant that the cleanup of the SILOE foundation raft had not, at this stage, achieved the cleanliness targets initially set. For its part, ASN did not favor managing this situation through the implementation of a "public service easement ${ }^{263 "}$. Furthermore, full cleanup required in-depth treatment that could affect the mechanical strength of the reactor building. This is why the CEA ultimately decided to fully demolish the dome and cylindrical walls of the reactor building, as well as the auxiliary buildings, before completely removing the basemat and the contaminated soil. The corresponding work is illustrated in figure 10.2.
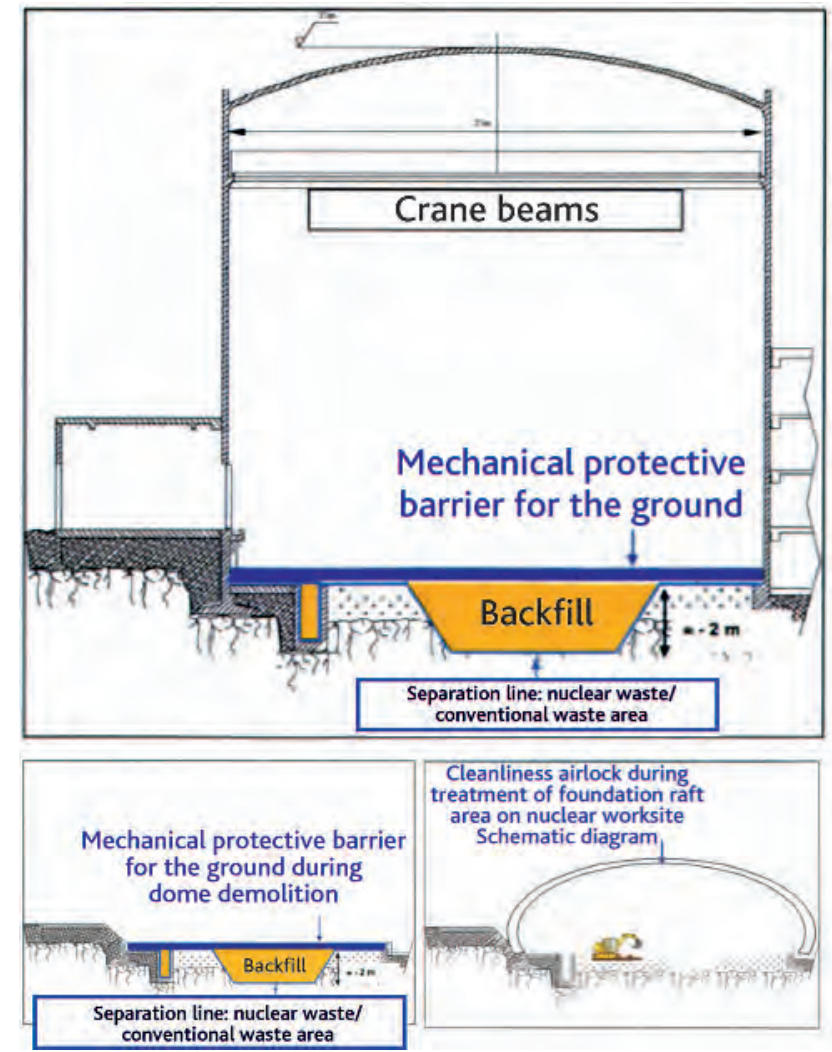

Figure 10.2. Some of the dismantling stages of the SILOE reactor (2010s). ( ) All rights reserved.

263. A public service easement is an administrative easement appended to the land use plan in accordance with article L. 126-1 of the French planning code. An impact study is also produced. 
The soil below the SILOE reactor basemat had to be excavated to a depth of $1.8 \mathrm{~m}$.

The license governing the permanent shutdown and dismantling of the SILOE reactor was modified ${ }^{264}$ to take into account new cleanup work that would extend the duration of operations. The SILOE reactor was decommissioned ${ }^{265}$ by an ASN resolution dated January 8,2015 , ratified by an order of the minister in charge of nuclear safety dated February $12,2015^{266}$.

\section{- Melting of fuel plates in the SILOE reactor $(1967)^{267}$}

On November 7, 1967, six fuel plates in a control element ${ }^{268}$ partially melted in the SILOE reactor during a power increase to $42.3 \mathrm{MW}$ performed as part of preparatory tests for taking nominal reactor operation up to $30 \mathrm{MW}^{269}$. These tests, authorized by the $\mathrm{CSIA}^{270}$, notably aimed to determine the power margins available in relation to the "flow redistribution" phenomenon in fuel elements (described in detail below). At 42.3 MW, a sudden drop in power was observed of approximately $7 \mathrm{MW}$ in one second, followed by a slower drop until it stabilized, 20 seconds later, at $20 \mathrm{MW}$. The reactor was shut down manually 26 seconds later by dropping two safety absorbers. A rapid increase in $\gamma$ radiation dose rates was then observed (in an immersed measurement chamber, up to $1,000 \mathrm{rad} / \mathrm{h}$, and in another measurement chamber, located above the pool water, up to a value of $220 \mathrm{rad} / \mathrm{h}$ ), which led to the evacuation of the reactor building and auxiliary buildings, as well as the use of the iodine filters on the emergency ventilation system.

This event caused $187 \mathrm{~g}$ of uranium and aluminum alloy (enriched to $93 \%$ uranium-235) to melt, corresponding to a mass of $36.8 \mathrm{~g}$ of uranium-235, $18 \mathrm{~g}$ of which was released into the reactor coolant system. The remainder was found in the form of magma at the bottom of the control element (figure 10.3).

Approximately $74 \mathrm{TBq}$, chiefly noble gases, were released via the reactor stack in the two days following the event. Contamination of both the reactor building and the site was negligible, due to the low burnup (4\%) of the element concerned. The fuel dispersed in the reactor coolant system was recovered in the decay tanks on the occasion of tank inspections performed in 1970 and 1971.

The cause of melting was not clearly established. In this respect, the results of the investigations carried out by the operator following this event, which notably involved measuring the temperature of the same type of control element cladding positioned in the location where the melted fuel plates were found, at powers of between 0 and

264. Decree 2013-677 of July 24, 2013.

265. Removed from the list of INBs.

266. Official Journal of the French Republic of February 20, 2015.

267. Contrôle review 128, April 1997, ASN.

268. Fuel element containing an absorber for power control.

269. Since commissioning in 1963, the reactor had operated at a nominal power of $15 \mathrm{MW}$.

270. "Commission de sûreté des installations atomiques" (nuclear facility safety commission), France. 

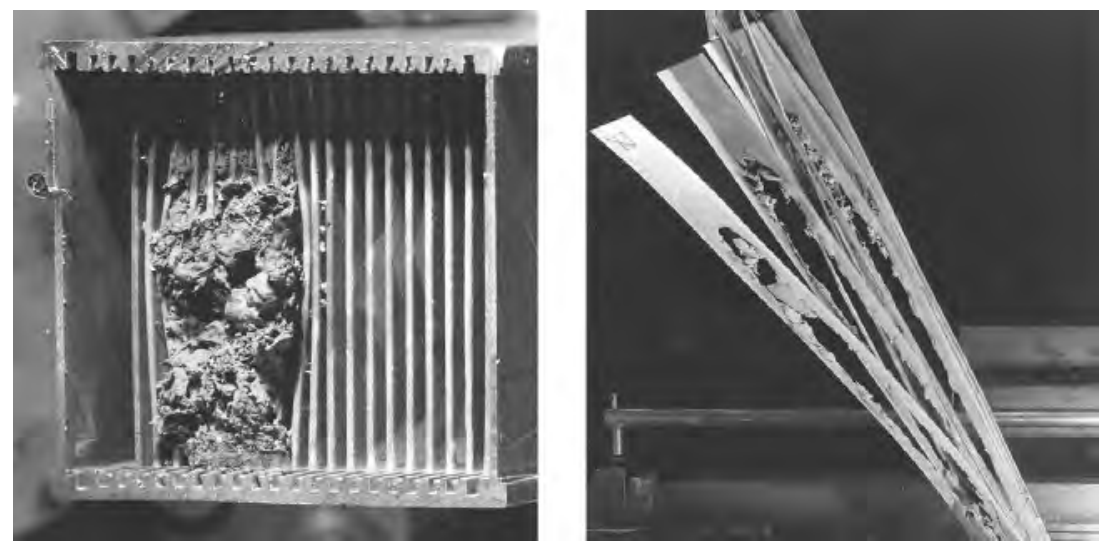

Figure 10.3. Two views of the melted plates in the control element at the SILOE reactor. (C) ILL.

$39 \mathrm{MW}$, seem to rule out the flow redistribution hypothesis ${ }^{271}$; indeed, the extrapolation of these measurements to $42.3 \mathrm{MW}$ gave, for the melted plates, a temperature at the hot point of the cladding below that corresponding to local boiling $\left(116^{\circ} \mathrm{C}\right.$ as opposed to $128^{\circ} \mathrm{C}$ ). In addition, the hottest plate of the control element did not melt.

As flakes of dry paint, from the structures located over the pool, were discovered several times on the core elements, the operator finally attributed the melting of the plates to the partial blockage of several cooling channels on the control element concerned.

The following improvements were made after this event:

- the painted sheet metal structures overhanging the core, used for routing the cables and hoses of experimental devices, were replaced with stainless steel structures;

- a second emergency exhaust system was installed at the facility to improve the reliability of this safety-related system;

- systems were installed to allow the air above the pool and the water from the pool to be sampled from outside the reactor building;

- controls for the pool water purification system were installed in the control room.

Decontamination was not required following this event. Authorization to restart the reactor was granted a few days later.

271. Phenomenon that can result in local overheating and boiling, resulting in a change in water flow between the plates. Various tests performed in the CABRI reactor had already shown that, in general, flow redistribution is accompanied by power oscillations due to local boiling and the corresponding vacuum effect; such oscillations were not observed during the event reported here. 


\section{Explosion of the AQUILON experimental irradiation device in SILOE} (1979)

The explosion of the AQUILON experimental irradiation device occurred at the SILOE reactor on April 10, 1979. This device - similar to the "boilers"272 used for tests on light water reactor fuel - was positioned at the edge of the core and contained an irradiated uranium oxide fuel rod $\left(\mathrm{UO}_{2}\right.$; uranium enriched to $4.7 \%$ isotope 235$)$. The explosion of the device caused uranium oxide and fission products to be released into the reactor pool, and noble gases and iodine to be released into the reactor building and environment.

In the device (figure 10.4), the water was practically static ${ }^{273}$; its pressure was adjusted depending on the heat released by the fuel rod in such a way as to achieve

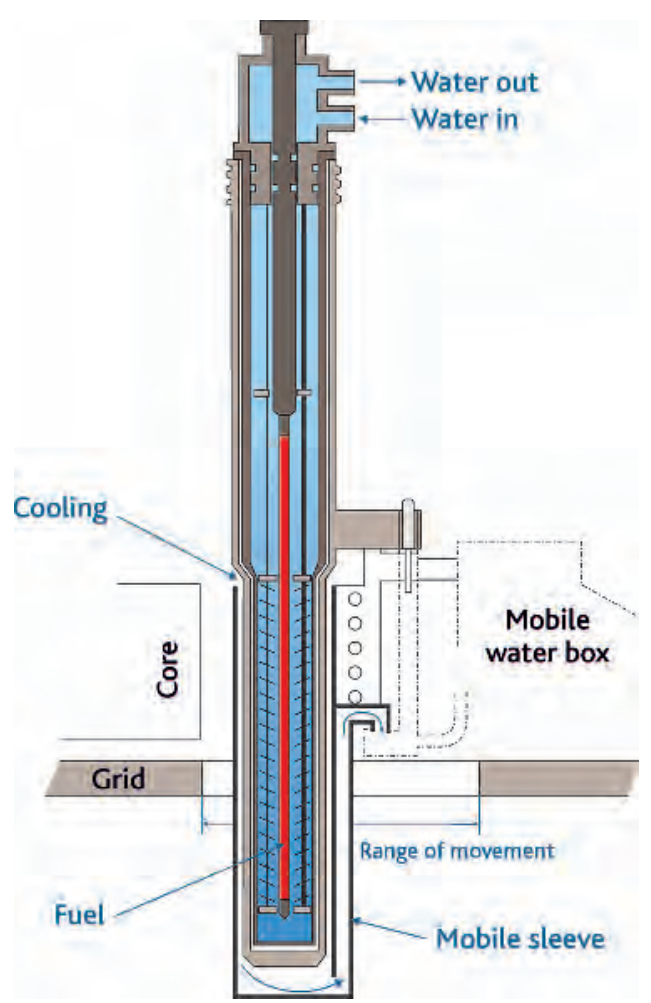

Figure 10.4. Section view of AQUILON device (c) Georges Goué/IRSN.

272. The pressure inside the AQUILON device had reached 130 bars, as opposed to 78 bars in the "boiler devices".

273. The device was not equipped with a water circulation pump, meaning that only natural convection was possible. 
nucleate boiling. The superheated steam produced was directed by the rod guide rings to the cold wall of the device, where it condensed. The external wall of the device was cooled by circulating water from the pool. For this purpose, a cooling channel $(2 \mathrm{~mm}$ "thick") was created by positioning a cylindrical sleeve around the lower part of the device in line with the SILOE reactor core. This was connected to the reactor coolant system via a mobile "water box" (allowing the device to be moved closer to or further away from the core). The sleeve, weighing approximately $10 \mathrm{~kg}$, rested on the "water box", but was not mechanically fastened to it.

Reactor shutdown could be triggered automatically by security devices linked to the loop (in the event of the tube breaking under high pressure, or in the event of low water level in the pressurizer, or even high temperature in the lower part of the device).

On April 10, 1979, at 9:17 am, the device had been positioned away from the core for around 17 hours (the security devices were disabled via "shunts") and the reactor was in operation. Three handling operators were removing the device using an overhead crane.

At 9:20 am, the order to evacuate the reactor hall was given from the control room, as the second dose rate threshold (set to $0.25 \mathrm{mGy} / \mathrm{h}$ ) had been exceeded at a $\gamma$ radiation measurement chamber located over the pool. Five minutes later, an explosion was perceived in the control room and the two safety absorbers dropped. Almost simultaneously, the alarm and safety thresholds of numerous radiation measurement channels were exceeded. Orders were given to evacuate the building (with the dose rate reaching $0.4 \mathrm{mGy} / \mathrm{h}$ in the control room) and these were followed once the operators had ordered the three control absorbers to be dropped, the reactor coolant pumps to be stopped and the emergency air exhaust system to be started (for reactor hall ventilation with iodine filters).

The following observations were made during the subsequent investigations:

- the device sleeve showed signs of heating and had two holes;

- the test fuel rod was partially melted;

- the upper part of the external plate of a fuel element located near the device "water box" was deformed, without cladding failure.

Approximately $190 \mathrm{~g}$ of $\mathrm{UO}_{2}$ (7.5 g of uranium-235) was expelled from the device into the pool.

The explosion of the device notably led to $18.5 \mathrm{TBq}$ of fission products being released into the pool. The environmental releases were estimated at $2.6 \mathrm{TBq}$ of noble gases and approximately $7.10^{8} \mathrm{~Bq}$ of iodine, $10^{8} \mathrm{~Bq}$ of which was iodine 131 . Due to the rapid evacuation of the reactor hall by the three handling operators before the explosion, the dose received by the most exposed worker was limited to $1.8 \mathrm{mGy}$. The maximum activity concentration of gaseous releases via the reactor stack was 1.48.10 $\mathrm{Bq} / \mathrm{L}$ (xenon). The measurements taken in the environment, downwind, did not indicate any activity due to aerosols or iodine above the natural background noise.

The cause of the event was determined: the sleeve had shifted when the AQUILON device was being removed, which had: 
- interrupted device cooling (uncoupling of the connection between the sleeve and "water box");

- stopped the cooling water guide function usually performed by the sleeve, until the lower part of the device was completely outside the reactor core.

Moreover, it was not possible to confirm whether the pressurizer valve on the device had worked correctly.

All the fuel elements in the SILOE reactor core were checked using a mobile cladding failure detection device. The six elements closest to the AQUILON device were replaced. Authorization to restart the reactor was granted by the SCSIN after a shutdown lasting ten days, largely spent purifying the pool water. However, the use of "boiler"-type devices was suspended, notably to assess the status of these devices in relation to pressure equipment regulations.

The general measures taken by the CEA after the event - following the meeting of the reactor safety commission on July 11, 1979 - notably included:

- banning the use of "shunts" on safety systems associated with experimental devices during their removal from or insertion into a core;

- requiring sleeves to be fastened to "water chambers";

- ensuring that procedures for inserting or removing various devices into or from a core, with the reactor in operation or shut down, were made more comprehensive and detailed.

\section{Underestimation of the operating power of RHF (1971-1990)}

An ongoing anomaly in which the real operating power of RHF (Grenoble) was underestimated by around 10\% was discovered in January 1990 after some reactor operating parameters were checked. Following this observation, the operator reduced this operating power in order to comply with the maximum value of $58.3 \mathrm{MW}$ th set out in the operating rules.

This anomaly was declared to the SCSIN on January 23,1990 . It arose due to an error in the calculation of the heavy water flow rate in the main reactor system. The formula used, established on the basis of measurements performed using light water, had not been corrected to take into account the difference in density between light water and heavy water. In fact, the real flow rate was $10 \%$ higher than the flow rate calculated. This error had also been made when the reactor protection system thresholds were determined, meaning that there was no automatic reactor alarm or reactor scram.

On January 24, 1990, the SCSIN ordered the operator to keep the reactor shut down ${ }^{274}$, with restarting subject to SCSIN authorization.

274. The operator, which had initially lowered the reactor power, ultimately decided to shut down the reactor. 
It became clear that observations made previously by the operator could be explained by this underestimation of the operating power. Indeed, the operator had observed that fuel was consumed more rapidly than expected, resulting in shorter operating cycles (the control rods reached their post-irradiation position after 42 days, instead of 46 days as expected).

This anomaly led the operator to fully review the studies on the core physics of RHF (neutronics and thermohydraulics).

\section{Melting of fuel in driver core rods in the CABRI reactor (2004) 275276}

As part of the safety review associated with the project to modify the CABRI facility to allow tests in a pressurized water loop, examinations were performed on the hottest fuel rods in the reactor core. During the first non-destructive examinations performed on three of these rods, folds were observed on their cladding. The amplitude of these folds measured several tens of micrometers and the pitches (the distance between folds) were close to $10 \mathrm{~mm}$ - approximately corresponding to the height of a fuel pellet - on the lower part of the three rods. For two of the rods, a significant area of deformation of a few per cent was observed above the fold area.

After these observations were made, a radial cross-section was taken across the area of maximum deformation of one of these rods. A macrograph of this cross-section showed the presence of local melting at the center of the fuel and signs of pelletcladding interaction. These observations constituted deviations from the technical requirements for the CABRI reactor and were reported to the French Directorate for Nuclear Safety (DSIN) on January 12, 2004.

As indicated in chapter 5 , the CABRI reactor was designed for power excursions ("pulses" - see figure 10.5) from maximum steady-state operating conditions of $25 \mathrm{MW}$. With a view to preventing the fuel melting, and ensuring the leaktightness of the cladding of rods in the driver core, the technical requirements for the facility stated that, during these power excursions, the maximum fuel temperature should not exceed $2,400^{\circ} \mathrm{C}^{277}$, all uncertainties combined, and the surfacic thermal power of the core rods ${ }^{278}$ should remain below $750 \mathrm{~W} / \mathrm{cm}^{2}$ (criteria to be respected in estimates via calculation, prior to experiments). In addition, these technical requirements authorized reactor operation above $25 \mathrm{MW}$ up to $42.5 \mathrm{MW}$ for a maximum cumulative duration of 23 minutes in order to perform slow power ramps; in these conditions, the maximum temperature of the fuel should not exceed $2,768^{\circ} \mathrm{C}$, all uncertainties combined (requirements indicated in the safety report, justified by calculations).

Since the CABRI reactor went critical in 1977, around 500 rapid power transients ("pulses") and 16 slow power ramps above $25 \mathrm{MW}$ had been performed with the driver

\footnotetext{
275. ASN website, incident reports.

276. Summary of the IRSN report on restarting the CABRI reactor, dated January 22,2009 , available to the public.

277. The melting point of $\mathrm{UO}_{2}$ is around $2,840^{\circ} \mathrm{C}$.

278. Value from tests (CAPRI) performed in a loop at the CEA in Grenoble.
} 


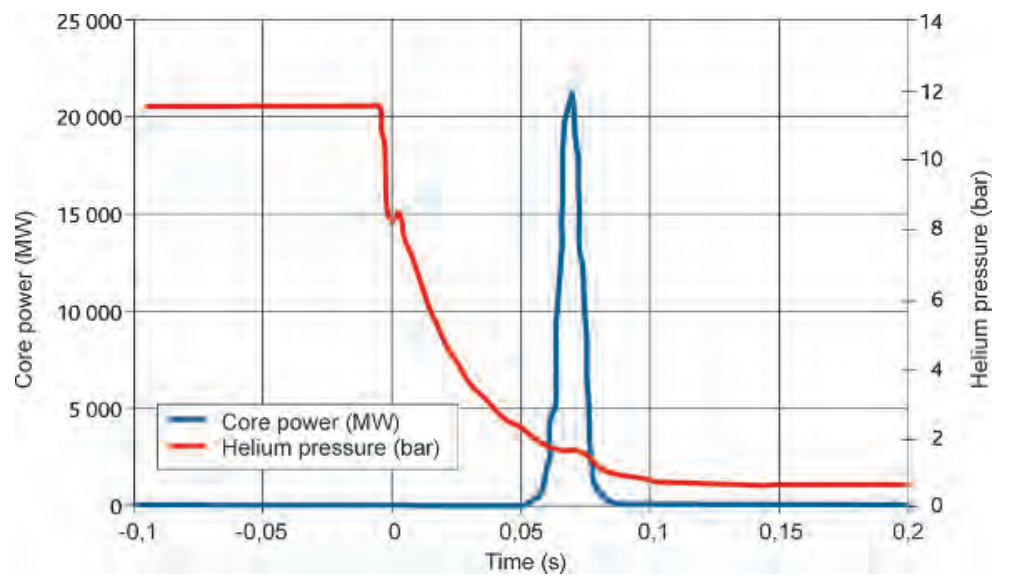

Figure 10.5. Example of a power-time profile for a "pulse" of power in the CABRI reactor. $\odot$ Georges Goué/IRSN.

core for a cumulative duration of 19.8 minutes. The average burnup of the reactor core was $88 \mathrm{MWd} / \mathrm{tU}$ (approximately 2.3 equivalent full power days [EFPD]).

The fuel in the reactor core is made up of $\mathrm{UO}_{2}$ at a low level of uranium-235 enrichment, in the form of pellets stacked in stainless steel cladding (grade $304 \mathrm{~L}$ as per the American AISI standard).

The following provisions were selected at design to limit the risk of fuel rod dryout during rapid power transients:

- the adoption of a high initial radial clearance between the fuel and the cladding to limit pellet-cladding interaction;

- the adoption of a cold internal helium pressure sufficient to prevent cladding creep at high temperature under the effect of external pressure;

- the selection of a special type of pellet ${ }^{279}$ unlikely to fracture under the effects of a radial thermal gradient (conservation of initial pellet geometry);

- the choice of steel cladding with a high expansion coefficient, which contributes to limiting the closure of the pellet-cladding clearance during power transients.

The good condition of the fuel had been checked previously by examining some of the hottest rods in the reactor core, firstly in 1988 after around 200 rapid transients had been performed, then in 1991 after nearly 10 minutes of cumulative operation above $25 \mathrm{MW}$ in slow ramps (out of the 23 minutes authorized).

After investigation, the cladding deformation and core fuel melt were attributed to slow ramp transients, which cause fuel pellets to deform into a diabolo shape; this

279. Using a sintering process that differs from that used for fuel pellets destined for reactor rods to be used in nuclear power reactors. 
means that in the event of pellet-cladding interaction during such transients, folds may appear in the cladding (rapid power transients cause the pellets to deform into a barrel shape). In addition, only slow ramps heat the fuel to a temperature close to its melting point, leading to the conclusion that the deformations observed had probably appeared after the tenth minute of operation above $25 \mathrm{MW}$.

The observations made raised a number of questions regarding safety, ultimately concerning in fine the capacity of the CABRI reactor driver core to undergo the tests planned for the future (10 rapid transients as part of the CIP program ${ }^{280}$ ):

- What was the overall state of the reactor core?

- What measures were needed to return the core to compliance?

- What additional measures were needed for the in-service monitoring of the core fuel rods?

- Was the distribution of power released in the reactor core well known?

- Did the simulation tools used to check, before each new test, that the fuel and cladding criteria would be observed give reliable results?

- Should there be restrictions on using the reactor in future programs?

Given the involvement of IRSN in the research performed using the CABRI reactor, the files drawn up by the operator, the CEA, had been examined, at the request of IRSN, by the Belgian nuclear safety body, AVN (Association Vinçotte-Nucléaire).

In the light of the observations on the three rods mentioned above, an "extended inspection" approach ${ }^{281}$ was taken. Non-destructive examinations were therefore also performed on six additional rods taken from among the 1,488 rods in the CABRI reactor core; only minor deformations in their cladding were observed.

The reactor was returned to compliance by replacing four rods (the one subjected to destructive expert assessment, and the other three rods producing power similar to that produced by the assessed rod) with new rods. It was estimated that there was no risk of damage to the other reactor core rods, as they were not producing sufficient power.

In addition, a detailed analysis of the transients experienced by the reactor core made it possible to attribute the fuel melt and associated deformations to a slow ramp transient performed in 1995. The CEA then took the decision to perform no more slow ramp-type tests in the CABRI reactor.

The analyses performed showed that important parameters had been poorly estimated by the various software tools used to simulate fuel rod behavior as part of the safety analyses performed prior to the scheduled transients. This explains why the fuel melt had not been anticipated. A new simulation tool was then developed by the CEA (covered in more detail in chapter 11). In addition, based on the fact that

280. Cabri International Program. See "Current state of research on pressurized water reactor safety", Sciences and Technology Series, IRSN/EDP Sciences, 2017.

281. Standard approach not specific to research reactors. 
the number of transients experienced by the reactor core had subjected the fuel rods to greater loads than would be possible in the future, without any detection of cladding failure, the CEA suggested that, in the future, the demonstration of the absence of cladding failure during a transient could be based on ensuring compliance with two criteria associated with circumferential deformation and cladding temperature. This was accepted, notably given the good ductility of the austenitic steel used for the cladding of fuel rods for the CABRI reactor, only slightly irradiated, as well as the low quantity of fission products accumulated in this fuel. In this respect, IRSN performed a study, during the expert assessment of CEA files, to compare the energy that a reactor core rod should produce during a rapid transient to achieve the new criteria at the energy level representative of a cladding failure limit determined on the basis of tests performed in the USA and Japan ${ }^{282}$; this study showed that these criteria were consistent for the transients expected in the CABRI reactor (CIP program).

Lastly, the results of the calculations performed using the new simulation tool made it possible to demonstrate that the cladding deformations and cladding and fuel temperatures should not result in cladding failure during CIP program tests.

In terms of in-service monitoring, the program selected by the CEA for the rods in the CABRI reactor core includes:

- establishing a "point zero" reference. This first step has been performed and involved performing a reference profilometry ${ }^{283}$ on the four rods substituted for those that experienced local melting (located in two control and safety rod [BCS] assemblies $^{284}$ );

- performing a profilometry at the end of the CIP program. This second step will involve unloading one of the two BCS assemblies containing the hot rods and removing one of them for profilometry. If there is a significant change (fold height greater than $60 \mu \mathrm{m}$ ), the inspection will be extended to two other hot rods in the BCS assembly. However, a slight change in the folding is to be expected, as the substitute rods (already irradiated) were not, by definition, in the hot spot position. The bounding "pulse" for future tests should therefore generate folding in the cladding of the new hot rods of around 60 to $100 \mu \mathrm{m}$ according to the predictive thermomechanical calculations.

\section{Exposure of workers to radiation}

Between 1973 and 2014, there were 18 events in which workers were exposed to radiation $^{285}$ at French research reactors (less than one event of this type per reactor

282. SPERT-CDC tests in the USA and NSRR tests in Japan, performed in 1969 and the 1970s with different cladding materials, including stainless steel as used for the driver core rods in the CABRI reactor. These tests led to the selection of a limit value, for rapid transients, of $240 \mathrm{cal} / \mathrm{g}$ for pressurized water reactor fuel rods.

283. Diameter measurements performed for two azimuths $90^{\circ}$ apart, based on a close axial pitch.

284. The driver core of the CABRI reactor has six assemblies, known as BCS assemblies or simply BCS, each with 21 fuel rods and 25 tubes containing control rods.

285. Including some (rare) contamination events. 
per decade). These occurred at six reactors, chiefly the SILOE, ISIS and OSIRIS reactors, as well as RHF. The change in the number of events over time is shown in figure 10.6 below.

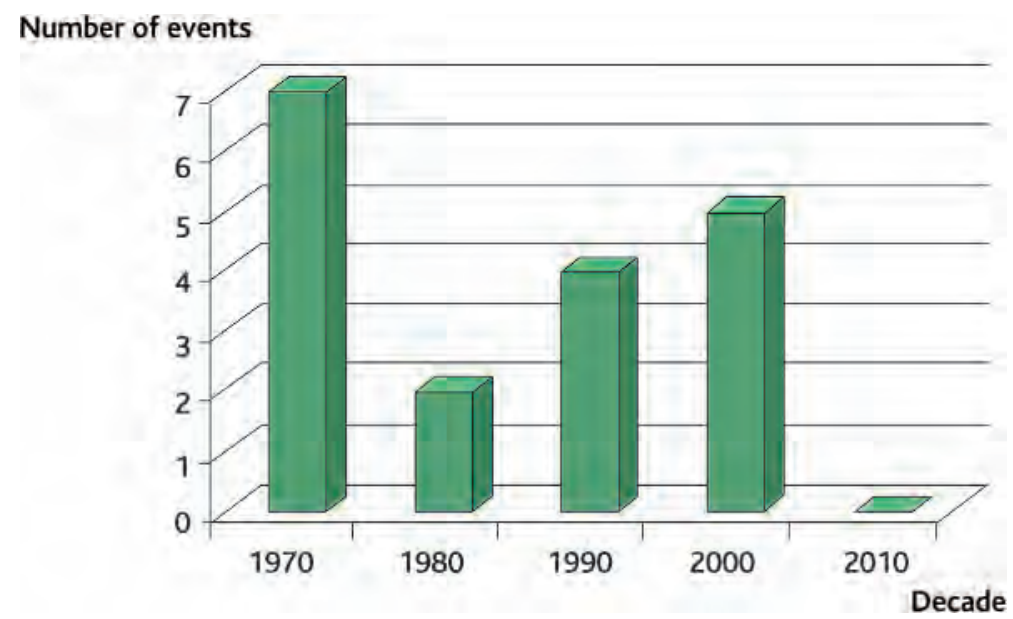

Figure 10.6. Change in the number of worker exposure events over the 1970s, 1980s, 1990s, 2000s and 2010s (2010-2014) in French research reactors. @ Georges Goué/IRSN.

Over a period of 41 years (1973-2014), around 30 people were exposed to radiation, with maximum doses in the order of $40 \mathrm{mSv}$, with the exception of the event that occurred at the SILOE reactor on November 15, 1979: when a photographic film was being placed on an activated dysprosium plate previously irradiated in the axis of a beam, an operator received a dose estimated at $140 \mathrm{mSv}$ (X-ray, $\beta$ and $\gamma$ radiation). Since 1990, there have been no cases in which workers have received significant doses of radiation (figure 10.7).

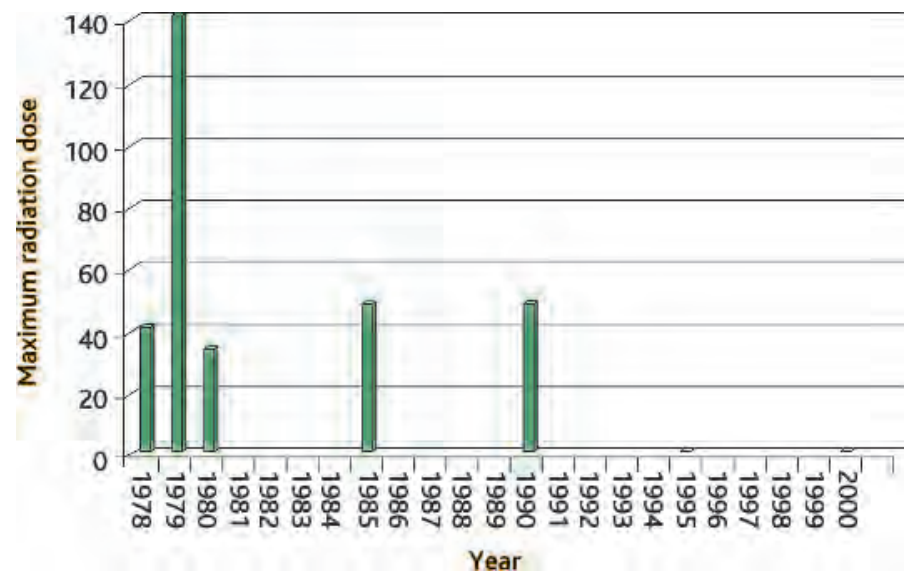

Figure 10.7. Change in the maximum radiation dose received by operators at French research reactors, in mSv $(1978,1979,1980,1985,1990)$. @ Georges Goué/IRSN. 
It is worth including here a description of one event that occurred at the SILOE reactor in October 1985, as it provides a general illustration of the risks that can arise when multiple activities are being performed simultaneously at one facility. The development of the film badge belonging to an external operator, who was working to restore the leaktightness of the reactor containment (metal structure), indicated that a dose of $47 \mathrm{mSv}$ had been received. The investigations carried out showed that this operator had been working on the reactor dome (metal containment), in line with a "hot cell" located in the reactor hall. At the same time, a cobalt 60 source of almost 100,000 Curies (for medical use) was being maneuvered in this cell using lifting equipment located on the roof of the cell, with the cable from this equipment passing through the thickness of the concrete via a narrow hole. During the operation, a very thin beam of ionizing radiation was directed towards the dome, affecting a small surface area of around $1 \mathrm{~m}^{2}$. The investigations also showed that this dose of $47 \mathrm{mSv}$ could be attributed solely to the period (20 minutes) when the source was being removed from the cell. After this event, the procedure for removing a source from the "hot cell" was updated to include a requirement to check that no work was being undertaken on the SILOE reactor dome at the same time.

There have been several events associated with the use of neutron channels at the ORPHÉE and RHF reactors. These have occurred more frequently at RHF due to the higher number of physics experiments performed simultaneously at that reactor ( 40 at RHF compared to 25 at ORPHÉE) and due to their duration, which is shorter on average at RHF.

Two events of this type, one in June 1989 at the ORPHÉE reactor - which could have led to the accidental exposure of personnel - and the other in August 1990 at RHF which led to the (low-level) exposure of two physicists and two operators (maximum dose in the order of $20 \mathrm{mSv}$ ) - are worth describing here as they illustrate the difficulties, mentioned in section 7.2.3, that arise when different populations are working at research reactors, namely operating personnel, on the one hand, and researchers, on the other. These two events led the relevant operators and IPSN to carry out an indepth analysis into:

- the technical measures for blocking the "neutron beams",

- human and organizational factors.

The technical measures for blocking the beams notably rely on the presence of physical shutters (a "head" shutter, positioned upstream of the neutron beam, and a secondary shutter ${ }^{286}$; these may use different technologies ${ }^{287}$ ), which make it possible to interrupt the neutron beam and re-establish continuous biological shielding for the reactor. These shutters, which are safety-related elements, are checked regularly. The two events in 1989 and 1990 highlighted shutter design anomalies (shutter off balance $^{288}$ due to a minor compressed air leak in the case of the ORPHÉE reactor, resulting

286. The neutron beam may, after a head shutter, be directed to several channels, each of them equipped with its own secondary shutter.

287. Flap, barrel, liquid plug, etc.

288. These were dual-action shutters in which the membrane was held in the closed position by pressurized air on each side. They have been replaced by spring and compressed-air shutters so that, if the air pressure drops on one side of the membrane, it is held in the closed position by the spring acting from the other side. 
in the untimely opening of the beam; shutter cut off [for operational reasons] from its compressed air supply at RHF, making it impossible to interrupt the beam). Various improvements have been made, notably to the compressed air systems controlling the shutters.

Regarding human and organizational factors, the event that occurred at the RHF reactor led IPSN, with the operator's agreement, to perform its own analysis. This gave rise to the following observations:

- the research physicists at the Institut Laue-Langevin had been put in a difficult position, as they received numerous requests to perform applied research experiments;

- three people in succession had persisted with an incorrect understanding of how the shutters worked and the role of a key used for the secondary shutter control rack, despite the visual and audio alarms, until a fourth person, the operator responsible for "managing" the shutters, had made them aware of the hazardous situation in which they were working. It therefore appeared that operator training regarding the shutter systems, their operating conditions and the associated monitors and alarms (visual and audio) was insufficient;

- the role of the internal security committee (CIS) in relation to experimental devices and experiments was limited at that time.

In the case of the ORPHÉE reactor, the coordination between the reactor operator and the Laboratoire Léon Brillouin ( LLB $^{289}$ ), where the researchers were based, had room for improvement; the facility manager was unable to properly exercise their safety responsibilities in relation to the experimental devices.

As a result of these two events, the responsibilities of the two relevant facility managers for the safety of people and property were extended to cover experimental devices within their basic nuclear installation, and the training of operators in charge of experimental devices was improved.

For the ORPHÉE reactor, an agreement was signed in September 1989 by the facility manager and the LLB, specifying the interfaces between the reactor facilities and the experimental devices, and making provision for the designation of a facility manager and safety engineer for experimental activities. This agreement also set out the respective responsibilities of this facility manager and safety engineer, and their relationship to the ORPHÉE facility manager. The experimental activities facility manager was given responsibility for the safety of people and property in the context of the general operating rules of the reactor, and charged with:

- training the operators involved in experimental activities,

- establishing the corresponding instructions and ensuring they are correctly applied,

- examining all significant modifications to existing experimental equipment and the implementation of new equipment, 
with the use of experimental devices (or the implementation of significant modifications to previously authorized devices) dependent on, as for RHF, an examination by the internal security committee (CIS).

\subsection{Measures to improve the safety of French research reactors following the Fukushima Daiichi accident}

The accident that occurred at the Fukushima Daiichi nuclear power plant on March 11, 2011, led the French Prime Minister to ask the Chairman of ASN, on March 23, 2011, to perform a study on the safety of nuclear facilities, prioritizing nuclear power reactors, in the light of this incident. The study had to cover five points: the risk of flooding, earthquake, loss of electrical power supply and loss of cooling, as well as the operational management of accident situations. The Prime Minister wanted this study to consider, facility by facility, whether safety improvements were required, in a way that was consistent with the work carried out in a European context by ENSREG and WENRA. He asked for the initial conclusions to be presented by the end of 2011.

At the same time, the European Council asked all the countries in the European Union, at its meeting of March 24 and 25, 2011, to perform "stress tests" on their nuclear power reactors, with regard to potential natural hazards (chiefly earthquakes and flooding) on a scale exceeding the characteristics considered in the design of the facilities (so-called "extreme" hazards).

In response to the Prime Minister's request, ASN ordered nuclear facility operators EDF, the CEA, AREVA and the Institut Laue-Langevin, through 12 resolutions taken on May 5, 2011, to present:

- "Provisions taken in the design basis of the facility and facility compliance to its design requirements ${ }^{290}$;

- the robustness of the facility beyond its design basis, by identifying, on the one hand, a step change in the event sequence (cliff edge effect) and, on the other, measures for its avoidance;

- proposals for modifications likely to improve safety of the facility and organization in the event of an emergency."

The studies performed in France by the operators constituted the "complementary safety assessments" (CSA).

As explained in section 7.3.2, the design of French research reactors allows them, as a general rule ${ }^{291}$, to reach, soon after shutdown, a state that requires no forced water flow and limited electrical power supplies (for facility monitoring, any releases, etc.).

290. This involved a full assessment of these areas, incorporating the elements and justifications in the safety reports (latest versions in force), any deviations or anomalies detected over time and their resolution, and past safety reviews.

291. Except in the case of the Jules Horowitz reactor. 
Furthermore, their radiological inventories are clearly significantly lower than those for power reactors. On the other hand, it is important to take into account their specific risks (construction in notable seismic areas or downstream of dams, near urban areas, etc.).

This is why CSA have been performed for research reactors, according to the specifications drawn up by ASN, based on those proposed by WENRA for the European power reactor stress tests, with an additional section on contractors providing services to operators. Priorities were, however, identified according to the risks associated with these reactors (taking a "proportionate" approach).

Regarding subcontractors, the Fukushima Daiichi accident showed that the capacity of an operator and, where relevant, its subcontractors to organize work in severe accident conditions is a key element of controlling such situations. This organizational capacity is also a key element of preventing such accidents, maintaining facilities and ensuring the quality of operations. As a result, the conditions of recourse to subcontractors are of special importance, and must allow the operator to retain full control over and full responsibility for the safety of its facility. It became clear that this aspect also needed to be covered in the CSA (the subjects to be covered by French operators are described in the focus section at the end of this chapter).

The complementary safety assessments involved assessing the behavior of research reactors in response to extreme hazards, chiefly earthquakes and flooding, as well as in the event of the loss of off-site electrical power or the off-site heat sink ${ }^{292}$, and in the management of severe accidents, in a context in which all or part of the facilities at a site may be affected over the long term.

It should be noted that all the CSA performed in France, whether at power reactors or research reactors (or other types of INBs), should be situated in the general context of work to improve their safety, which is based on:

- the integration of operating experience feedback,

- the ten-yearly safety reviews, which include the reassessment of safety rules and requirements based particularly on advances in knowledge.

In general, although they concluded that their facilities were well enough designed to withstand plausible natural hazards, the operators of research reactors proposed introducing a series of additional provisions, chiefly to increase the autonomy of the measures planned at the corresponding sites to deal with ongoing situations that could affect the long-term cooling of the reactor ${ }^{293}$ - which could arise from a loss of electrical power - or to strengthen the provisions for managing a large-scale emergency.

More specifically, the operators of French research reactors assessed the margins available, beyond the reference seismic loads ${ }^{294}$, for essential safety-related equipment items (sometimes referred to as "key SSCs"), such as reactor buildings and pools, natural convection valves, safety valves for neutron channels, etc. The behavior of equipment

292. Water from outside the facility that can be used to remove the heat released by the reactor.

293. For example, without special cooling measures, the gradual evaporation of water from a reactor pool would make it necessary to provide makeup water to avoid core uncovery.

294. Loads identified during the most recent seismic reviews. 
likely to jeopardize, in case of failure, these "key SSCs" has also been examined (overhead cranes in particular).

The expert assessment of the CSA sent to ASN by the operators of French research reactors was performed by IRSN; ASN also sought the opinion of the standing group of experts for nuclear reactors (GPR).

The margins estimated by the research reactor operators led ASN to rule that the facilities could continue operating, but that improvements should be made to obtain a "hardened safety core" (see the focus section below) of particularly robust equipment items, in order to withstand extreme hazards, such as an earthquake (hardened safety core design-basis earthquake [SND]) and its effects. The operators of research reactors were formally ordered to implement these "hardened safety cores" in 2013 through ASN resolutions. These "hardened safety cores" must aim to:

- "prevent a severe accident or limit its spread,

- mitigate large-scale releases,

- enable the licensee to fulfill its emergency management duties,"

through appropriate measures to strengthen defense in depth.

Regarding the last point above, it became clear in particular that there was a general need to strengthen post-accident monitoring provisions at research reactors in terms of analyzing the state of these reactors in extreme situations, for instance in order to obtain information regarding the position of the natural convection valves or safety rods.

In its 2013 resolutions, the ASN issued requirements regarding the situations to be taken into account when designing "hardened safety cores", specifically the "hardened safety core design-basis earthquake":

- The situations (known as "hardened safety core situations") to be taken into account are:

- the loss of electrical power supplies that do not form part of the "hardened safety core",

- the loss of the heat sink (reactor cooling) that does not form part of the "hardened safety core",

- the external hazards identified for the "hardened safety core",

- situations arising from the state of the facility, the site and its environment after one or more external hazards identified for the "hardened safety core".

- The hardened safety core design-basis earthquake must:

- encompass the seismic margin earthquake (SMS) for the site, augmented by $50 \%$,

- encompass the spectra established using a probabilistic approach for a 20,000 year return period,

- take into account special site effects, notably soil type. 


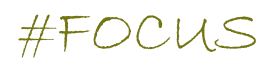

\section{The "hardened safety core" concept}

Safety improvements to facilities such as nuclear reactors, in the light of lessons learned from the accident that occurred at the Fukushima Daiichi nuclear power plant in March 2011, aim to limit, as far as possible, short-, medium- and long-term radioactive releases in the event of an extreme external hazard with the long-term loss of electrical power and the heat sink at a site. Indeed, in such situations it is desirable that a nuclear facility avoid adding to the difficulties already facing the emergency teams responsible for assisting the population. In the event of a natural catastrophe of the kind that occurred in Japan in March 2011, the environment of the affected site would be severely damaged, making it difficult to take action to protect the site's neighboring populations and, in the long term, manage the contaminated area.

The post-Fukushima "hardened safety core" therefore contains provisions to guarantee all the fundamental safety functions in the situations mentioned above ("hardened safety core situations").

In addition, it has become clear that the "hardened safety core" should be defined by considering the loss of all the provisions already implemented as part of in depth defense, whose robustness to natural hazards significantly more extreme than those identified during facility design cannot generally be established with great certainty.

This means that the "hardened safety core" includes provisions sufficiently robust to prevent, as far as possible, the fuel melting (in the core or storage pool) ${ }^{295}$ in the situations mentioned previously; this involves stopping the nuclear chain reaction and maintaining fuel cooling, and implementing measures to limit releases in such a way that reduces the radiological consequences in the event of the fuel melting, in terms of scale and duration. It must also be possible to guarantee that the operator can perform the duties required of it in emergency situations. To do this, the "hardened safety core" provisions must ensure that emergency teams can access the information needed to assess the state of the facilities and prepare for on-site operations. In the event of radioactive releases into the environment, the operator must also be able to assess the consequences of these releases using not only the data available from the facilities, but also measurements performed in the environment (meteorological, dose rate and radiological activity measurements). This information must allow the operator and public authorities to make the decisions for which they are respectively responsible in order to protect the personnel present at the site and the general public. In this respect, it is therefore vital for the site to have operational external communications systems in the situations under consideration.

$295 . \quad$ Principle applied in the various ASN resolutions issued to operators in 2013. 
In the definition of the "hardened safety core", attention must also be paid to the "support systems", which enable the operation of systems that directly perform safety functions. These notably include electrical power generation and distribution systems (generators or batteries, electrical switchboards), instrumentation and control systems, and ventilation systems (which perform the thermal conditioning functions for rooms). For these systems, the aim is to ensure independence and diversification in relation to existing systems.

For existing nuclear facilities, or facilities in an advanced state of design or construction (Flamanville 3 [EPR], the Jules Horowitz Reactor), it is not possible to ensure that the "hardened safety core" contains only new equipment. It will ultimately consist of existing structures, systems and components, strengthened if necessary to ensure that they remain operational in the event of an external hazard, and new structures, systems and components.

It is not easy to define the "levels" of extreme hazard to be considered when designing the "hardened safety core", especially in the case of seismic hazards. The traditional approaches used to assess seismic hazards have been supplemented with probabilistic methods, notably to target earthquakes associated with a 20,000year return period as requested by $\mathrm{ASN}$ in its requirements issued to operators.

The reports on the complementary safety assessments carried out by French operators, drawn up according to the plan described in the focus section below and incorporating the additional provisions proposed (relating to the "hardened safety core" in particular), have been made public ${ }^{296}$. It should be noted that, in some cases, these CSA brought to light instances of noncompliance (related to equipement items, studies, etc.) in relation to the "key SSCs", which therefore had to be resolved.

The RHF complementary safety assessment ${ }^{297}$ is covered in further detail below, given the specific features of this facility in terms of earthquake and flood risks, and its proximity to urban areas. For example, this CSA resulted in the facility introducing (in stages from 2012 to 2016) various systems designed and sized for the hardened safety core design-basis earthquake (see figures 10.8 and 10.9):

- a seismic reactor shutdown system (ARS);

- an emergency core flooding system (CRU) linking the reactor block, which has a limited volume $\left(15 \mathrm{~m}^{3}\right)$, to the large-volume reactor pool $\left(500 \mathrm{~m}^{3}\right)$;

- a groundwater supply system (CEN) to mitigate potential reactor core uncovery, with a flow rate of $250 \mathrm{~m}^{3} / \mathrm{h}$ (for each of the two channels), compared to just $60 \mathrm{~m}^{3} / \mathrm{h}$ for the emergency cooling system (CES) implemented in 2006;

- a new emergency ventilation system for the reactor building (seismic depressurization system [CDS]);

296. On the ASN website.

297. Rapport RHF $n^{\circ} 399$ on the ASN website. 


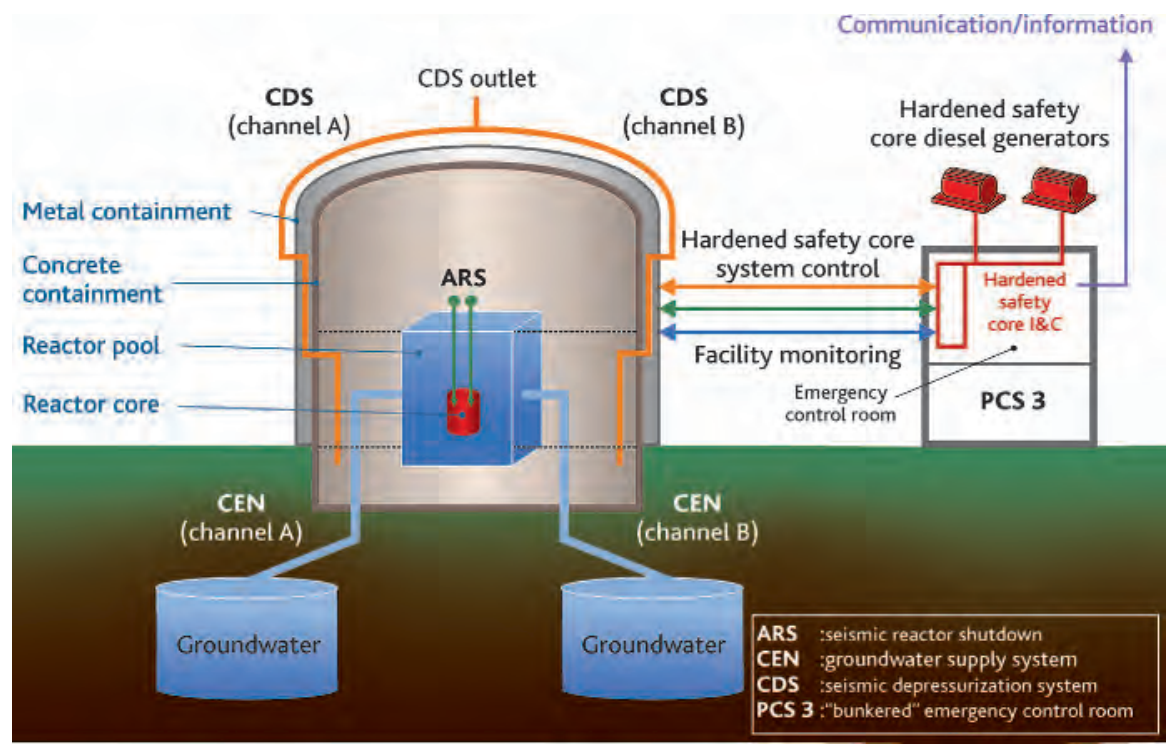

Figure 10.8. Schematic diagram of additional measures installed at RHF after the Fukushima Daiichi accident. () Georges Goué/IRSN.

- a new emergency control room (PCS ${ }^{298} 3$ building);

- specific equipment (in PCS 3) to monitor some key parameters of the state of the facility (the core neutron flux, with two new neutron detectors attached to the reactor block in the light water pool; the configuration of the natural convection valves; the water levels in the reactor block and pool; and the pressure in the reactor hall and in the annulus between the two containment walls), with the values also being automatically sent to $\operatorname{IRSN}^{299}$ in the event of an accident.

These systems, the majority of which are redundant ${ }^{300}$ and automatic, are electrically powered by emergency generator sets in the new PCS 3 building, which was designed to withstand not only the extreme hazards considered for the RHF site (hardened safety core design-basis earthquake, equivalent to twice the seismic margin earthquake at the relevant frequencies), but also the failure of the upstream dams (PCS 3 is positioned six meters higher than the HFR site platform). They have been fully operational since 2016.

Regarding the seismic reactor shutdown system, it is important to note that the instrumentation and control for the reactor protection system had already been adjusted to ensure that the safety rods ${ }^{301}$ drop automatically in the event of seismic

298. Poste de contrôle et secours [emergency control room].

299. To strengthen the analysis of the facility with the operator (in the context of implementing the 3D-3P approach mentioned in section 7.7).

300. There is only one PCS 3.

301. These are five control rods located in the reflector area, outside the fuel element that forms the reactor core in which the regulating rod slides. 

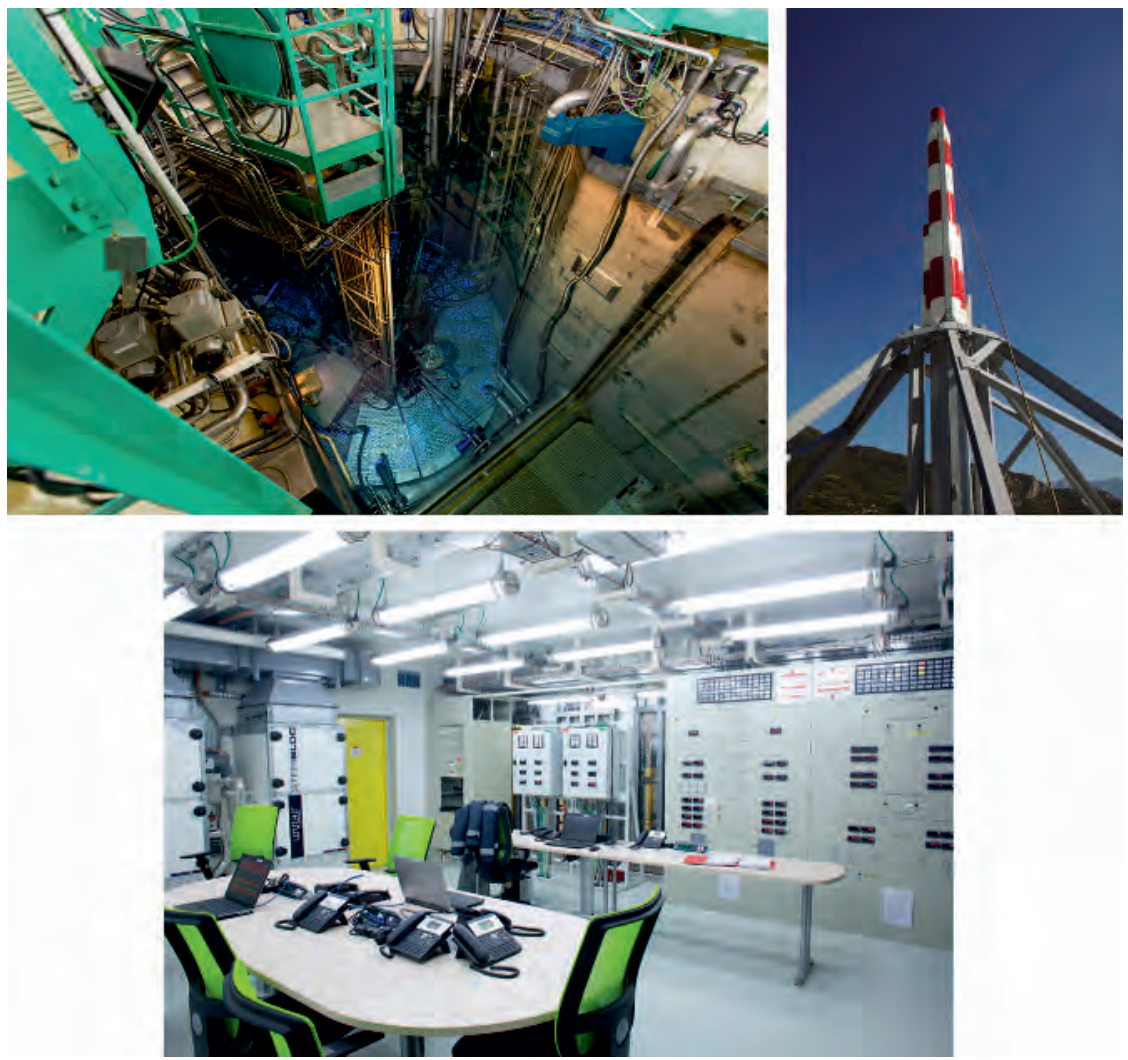

Figure 10.9. Three measures selected for the RHF at Grenoble after the Fukushima Daiichi accident, all designed and sized for extreme earthquakes and flooding: on the top left, the pool inlet elbow of the groundwater supply system. (C) IRSN; on the top right, the seismic depressurization system stack positioned on the dome of the metal containment. () ILL; at the bottom, the PCS 3 emergency control room. (c) Jean-Marie Huron/Signatures/IRSN.

loads, by setting the trigger threshold to $0.01 \mathrm{~g}^{302}$. It was then completely renovated to make it independent from the other reactor protection systems, and it was qualified for the "hardened safety core design-basis earthquake". This provision ensures that the safety rods drop - even in the event of an earthquake without a weak movement phase (compressional waves known as P-waves) before the strong movement phase (shear waves known as S-waves).

Still in the case of RHF, the operator studied two scenarios for failure of the dam(s) upstream on the Drac River, and their possible impact on the "key SSCs". They were:

302. The trigger threshold value for reactor scram is selected to be lower than the peak ground acceleration to allow sufficient time to implement this reactor scram. A value of $0.01 \mathrm{~g}$ is typically reached when the primary seismic waves ( $P$-waves) arrive; accelerations at the level of peak ground acceleration (several tens of $g$ ) are detected several seconds later, with the arrival of the S-waves, which cause the most damage to equipment. 
- failure of the Monteynard dam, which could lead to the failure of the NotreDame-de-Commiers dam downstream;

- failure of all the dams on the Drac River, which would result in the highest possible water level at Grenoble.

As a result of these studies, the operator considered a hypothetical water level of six meters at the RHF platform. This was taken into account in the design of the new emergency control room building (PCS 3). The large openings in the reactor building (truck entrances, etc.) were strengthened to ensure they could withstand a hardened safety core design-basis earthquake and a water level of six meters at the site, while maintaining sufficient leaktightness to prevent large quantities of water entering the building.

In the definition of a "hardened safety core design-basis earthquake", the issue of site effects is particularly relevant in the case of RHF, as the reactor is positioned in an alluvial valley (the alluvium is around $700 \mathrm{~m}$ above the bedrock, and partially composed of clay). This is why the operator has been involved in research into the site effects since the 2000 s (the CASHIMA project and, more recently, the SIGMA project ${ }^{303}$ ), and has had measurements (crosshole measurements ${ }^{304}$ ) and two-dimensional simulations performed with a view to better understanding these site effects. The multiplication factors applied to the spectra - which were previously established without taking the site effects into consideration - are between 1.3 (for frequencies above $3 \mathrm{~Hz}$ ) and 2 (for frequencies below $0.3 \mathrm{~Hz}$ ). The peak ground acceleration of the hardened safety core design-basis earthquake at infinite frequency is $0.6 \mathrm{~g}$, compared to the value close to $0.3 \mathrm{~g}$ identified during the seismic review in the early 2000s. Ultimately, at the relevant frequencies for structures, systems and components, the hardened safety core design-basis earthquake for RHF is twice as high as the seismic margin earthquake selected for the seismic reassessment in the early 2000 s.

The capacity of the "key SSCs" (overhead cranes, neutron channel safety valves, etc.) to withstand a hardened safety core design-basis earthquake was checked, including by vibrating table tests. This led the operator to strengthen:

- the overhead cranes for fuel casks,

- the large equipment near the edge of the pool (vertical "cold source", etc.),

- the cask maintenance station (potential hazard to the reactor containment),

- the large openings in the reactor building (truck entrances, etc.).

The operator of RHF decided to make some modifications to the "hardened safety core" as initially planned. In particular, these modifications involved rerouting the emergency ventilation system, rerouting cables to ensure they were not swept away in the event of extreme flooding (they are buried at a depth of 5 meters) and taking into account the chemical risks associated with the site environment. They also included designing the PCS 3 emergency control room to be habitable and operational in the

303. See "Current state of research on pressurized water reactor safety", Science and Technology Series, IRSN/EDP Sciences, 2017. Numerous European partners, both industrial operators and research organizations, including universities, are involved in these two projects.

304. Measurement of the velocity of the shear waves at a depth of $30 \mathrm{~m}$ - see the same publication. 
event of an accident involving phosgene release from the Pont de Chaix chemical platform (special ventilation/filtration system).

As mentioned previously, the "water block" principle was adopted for the design of the CEA reactors, such as OSIRIS, ORPHÉE and the Jules Horowitz reactor; this is a favorable design option for reactor cooling, as it guarantees that there is a sufficient volume of water in the reactor in the event of a leak in a section of core cooling system piping outside the reactor block. However, it is impossible to fully rule out the possibility, in extreme situations, of a loss of leaktightness in the rooms or bunkers in which these sections of piping are located, even though margins are built into the design of these rooms and bunkers ${ }^{305}$.

For reactors in operation (ORPHÉE, CABRI, etc.), various supplementary provisions have been proposed by the CEA: additional electric generator sets, makeup devices with a mobile water supply, additional measurement systems (water levels, etc.) and remote shutdown stations to monitor the facilities after an extreme hazard. In addition, strengthened provisions have been scheduled for 2015 to 2018 to allow effective emergency control even in extreme situations (setting up facility survey teams after an extreme hazard, strengthening or building rooms for equipment and systems that may be used in extreme situations).

For the Jules Horowitz reactor, the complementary safety assessments ${ }^{306}$ was performed by the CEA on the basis of the reactor design as of 2011. Various types of provision were selected for the continuation of the project, such as:

- the introduction of additional design margins for some items of equipment (new fuel storage rack anchors, rollers and tracks for the walkway over the reactor pool, etc.). In addition, measurement systems (natural convection valve position, water levels in pools and the reactor pool water temperature) were identified as "hardened safety core" equipment items;

- the decision to make available, in addition to emergency generator sets and the possibility of electrical power being supplied by a mobile set at the Cadarache center, a permanent ultimate diesel generator (GUS), qualified as "hardened safety core" (notably installed on a non-floodable platform);

- the creation of two connections on the emergency secondary cooling system to allow the supply of cold water from external sources (tankers equipped with an autonomous pump);

- the storage of a sufficient volume of water in the pool drain tanks for emergency water makeup to these pools, with this makeup system designed for the hardened safety core design-basis earthquake;

- the addition of a system for reactor scram in the event of an earthquake being detected.

305. Designed for the seismic margin earthquake.

306. File published on the ASN website: Réacteur Jules Horowitz - Évaluation complémentaire de la sûreté au regard de l'accident survenu à la centrale de Fukushima I [Jules Horowitz reactor Stress test following the Fukushima I accident] (CEA/DEN/CAD/DIR/CSN DO 575 13/09/11). 
\#FOCUS

\section{Subjects covered in the reports on the complementary safety assessments performed by operators after the Fukushima Daiichi nuclear power plant accident}

The complementary safety assessments reports were drafted based on the following standard format:

- site characteristics and current state,

- identification of cliff edge effect risks and essential structures and equipment:

The cliff edge effect is defined as a sudden change in the behavior of a facility caused by a slight change in the envisaged scenario for an accident, the consequences of which are then much more severe ${ }^{307}$.

- $\quad$ earthquakes: events considered (during design studies, then during safety reassessments), quantification of margins,

- external flooding: events considered (during design studies, then during safety reassessments), quantification of margins,

- other extreme natural phenomena,

- loss of electrical power and loss of cooling systems,

- severe accident management,

- conditions of recourse to subcontractors:

- the scope of the activities in question, with supporting arguments,

- the process by which subcontractors are chosen: requirements in terms of qualifications, training in nuclear safety and radiological protection, etc.),

- measures taken to allow for satisfactory working conditions for subcontractors, the organization implemented to provide radiological protection for workers,

- procedures for oversight of subcontracted activities, particularly the way in which the operator continues to assume responsibility with regard to nuclear safety and radiological protection.

- summary, including any proposals for supplementary measures.

307. Official Journal of the French Republic No. 0125 of May 31, 2012. 
